\title{
Characterization of Heat Activated Minerals from Puturge (Malatya, Turkey)
}

\author{
E. Izci
}

Physics Department / Anadolu University, Eskisehir, Turkey.

The samples were obtained from CimSa Mining Company operating industrial mineral deposits in Puturge- Malatya, Turkey. They were crushed, ground, and sieved to pass through a $\leq 63 \mu \mathrm{m}$ sieved. The samples were heated at 400,600 , and $950{ }^{\circ} \mathrm{C}$ for $3 \mathrm{~h}$ in air and then cooled to room temperature. Both the heating rates were $5.3{ }^{\circ} \mathrm{C} / \mathrm{min}$. Then they labeled as P400, P600, and P950.

Rigaku Rint 2200 powder diffractometer with $\mathrm{Cu} \mathrm{K} \alpha$ radiation was employed for XRD measurements. Infrared spectra of the unheated sample (P sample) and the heated samples (P400, P600, and P950) were recorded (1400- $400 \mathrm{~cm}^{-1}$ ) with Bruker Optics IFS66v/s FT-IR spectrometer at a resolution of $2 \mathrm{~cm}^{-1}$ at room temperature.

Figure 1 shows X-Ray diffraction patterns of the unheated sample (P sample) and sample P950. The major phase is quartz $(\mathrm{Q})$ with additional mineral phases of pyrophyllite $(\mathrm{P})$, kaolinite $(\mathrm{K})$, muscovite $(\mathrm{M})$, and paragonite $(\mathrm{Pr})$ in minor quantity. Presence of peak values at $\mathrm{d}(\mathrm{nm}) 0.4231,0.3333,0.2450$, $0.2227,0.2230,0.2122,0.1977,0.1932,0.1815,0.1669,0.1540$, and 0.1381 may be an indicative of the presence of quartz. Similarly the peak values at $d(\mathrm{~nm}) 0.973,0.3199$, and 0.2555 indicate the presence of muscovite. Unlike these, the peak values $d(\mathrm{~nm}) 0.362,0.236$, and 0.112 show the phase of kaolinite and the peak values at $d(\mathrm{~nm}) 0.654,0.3645,0.235$, and 0.163 show the phase of pyrophyllite. Also, the peak values at $d(\mathrm{~nm}) 0.362$, and 0.2628 show paragonite that is a type of mica such as muscovite. In the track of XRD of sample P950, new phases that cannot be seen in the sample P occurred. One of these phases is illite. The reason why kaolinite phase in the $\mathrm{P}$ sample is not seen in this P950 phase is that metakaolinite phase occurs [1]. Also, muscovite is a member of mica mineral group and its phase changes start when heat processes at $800-1000{ }^{\circ} \mathrm{C}$ are applied [2]. The reason why potassium mica phase is seen in the track of XRD of the sample P950 may be this crystal structure change.

FT-IR spectrum of $\mathrm{P}, \mathrm{P} 400$, and $\mathrm{P} 600$ samples is shown in the Figure 2. For the sample $\mathrm{P}$, the peak at $1121.49 \mathrm{~cm}^{-1}$ is an Al- OH stretching vibration [3] and the peak at $1071.43 \mathrm{~cm}^{-1}$ is the Si-O stretching vibration peak [4]. The peak at $1054.98 \mathrm{~cm}^{-1}$ corresponds to the intense $\mathrm{Si}-\mathrm{O}$ and $\mathrm{Si}-\mathrm{O}-\mathrm{Al}$ stretching frequencies, characteristic of aluminosilicates [3] and the peak at $952.72 \mathrm{~cm}^{-1}$ is the peak of Al-OH or $\mathrm{Si}-\mathrm{OH}[3,5]$. Furthermore, the peak at 801.36 and $841.87 \mathrm{~cm}^{-1}$ result from the vibration of Al-O and Si$\mathrm{O}$ out of surface $[4,6]$. The peak at $781.11 \mathrm{~cm}^{-1}$ is the Si-O stretching peak [3]. The peak at $542.55 \mathrm{~cm}^{-1}$ results from the bending vibrations of $\mathrm{Al}-\mathrm{OH}$. The band at $696.25 \mathrm{~cm}^{-1}$ is due to the deformation and bending modes of the $\mathrm{Si}-\mathrm{O}$ bond. Since there is no new formation, $\mathrm{P} 400$ and the sample $\mathrm{P}$ have the same phases and peaks. However, in the P400 sample, with the temperature increase for the heat application, water peaks start to move away from the structure [7] and the intensity of the Al-OH peak at 1121.49 $\mathrm{cm}^{-1}$ decrease. It is not seen in the P600. At sample P600, there is also a change in the absorption band at $541.95 \mathrm{~cm}^{-1}$. It is attributed to $\mathrm{Si}-\mathrm{O}-\mathrm{Al}$ bands. That change is related to the distortion of the silicate framework and it is specific for certain minerals [3]. In addition, four new absorption bands appeared at $865.01,735.79,654.79,567.71$ and $437.81 \mathrm{~cm}^{-1}$ at $600{ }^{0} \mathrm{C}$. These peaks are the small peaks. When heated at $950{ }^{0} \mathrm{C}$, the intensities of the $735.79,695.54,654.78,486.02,437.81,422.38$, and $408.88 \mathrm{~cm}^{-1}$ band increased. At this temperature, the peaks at 1087.78, 867.62, 782.08, and $488.92 \mathrm{~cm}^{-1}$ appear and 
these new peaks are Si- O- (Al, Mg, Fe possibly) The two bands at $567.03 \mathrm{~cm}^{-1}$ and $488.92 \mathrm{~cm}^{-1}$ assigned to $\mathrm{Si}-\mathrm{O}$ bending vibration $[6,7]$. In addition, the peak at $1125.38 \mathrm{~cm}^{-1}$ disappears (Figure 3 ).

References:

[1] AGS Cristobal et al, Materials Research Bulletin 44 (2009) p. 2103.

[2] F Gridi-Bennadji et al, Applied Clay Science 38 (2008) p. 259, 260.

[3] TK Mukhopadhyay, S Ghatak, and HS Maiti, Ceramics International 36 (2010) p. 913.

[4] C De-guang and SU Da-gen, Journal of Chongqing University 4 (2005) p. 72.

[5] M Erdemoglu et al, Applied Clay Science 27 (2004), p. 45.

[6] P Padmaja et al, International Journal of Inorganic Materials 3 (2001), p. 695, 696.

[7] T Jiang et al, Applied Clay Science 40 (2008), p. 85.

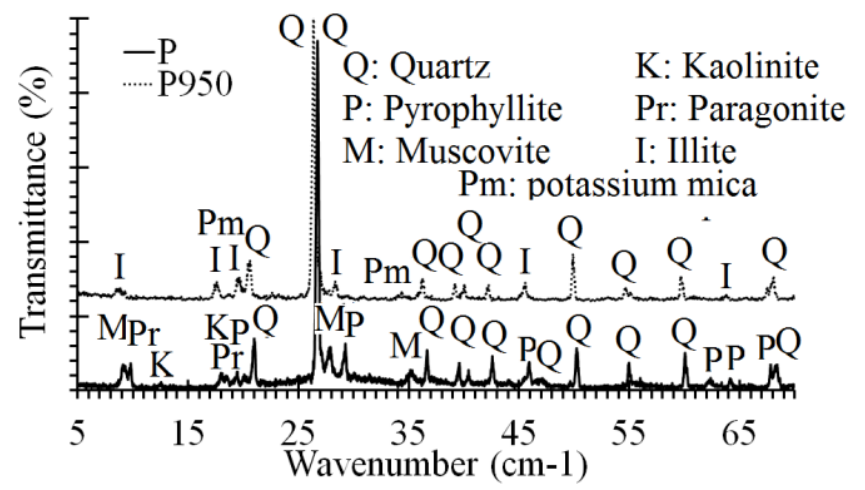

Figure 1. XRD patterns of the $\mathrm{P}$ and $\mathrm{P} 950$ samples

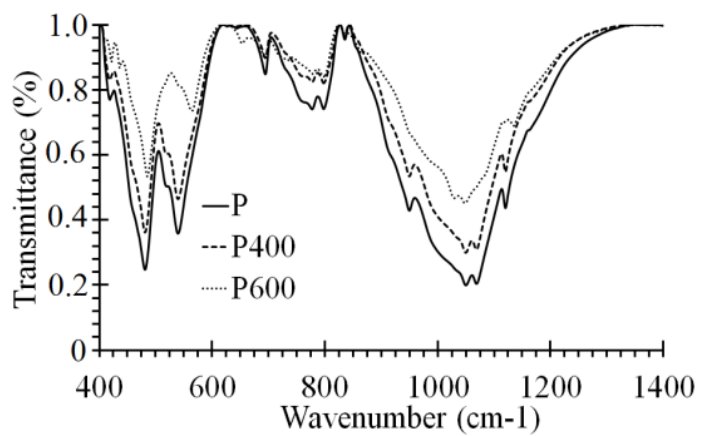

Figure 2. FTIR spectra of the P, P400, and P600 samples

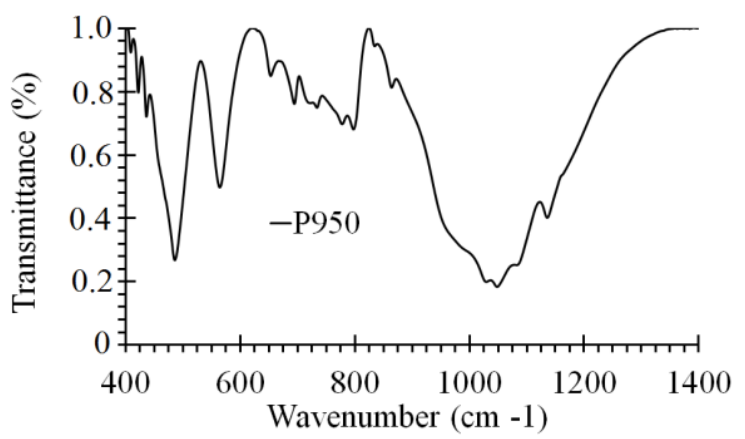

Figure 3. FTIR spectrum of the P950 sample 